\title{
RESPONSE BY ALYSSA GROSSMAN
}

$\mathrm{I}^{\mathrm{n}}$ a recent conversation I had with my collaborator Selena Kimball, we were discussing the uncertain disciplinary framing of our ongoing work together. 'In some ways,' Kimball told me, 'it's simple: I am an artist who incorporates (anthropological) research into my studio practice, while you are an anthropologist who uses artistic strategies and methods in your academic research.'The work that we make together-and to some extent the work we do on our owncould be defined as both anthropological and artistic, but it also runs the risk of being seen as neither.

I am not drawn to Calle's artistic practice because it embraces social and ethical transgressions that I as an anthropologist somehow yearn to enact but refrain from because of my professional codes of moral obligation. I am not particularly interested in the 'inappropriate' or 'anti-social' aspects of Calle's methods which, through the exposure of their own limitations, may allow them to be categorised within the genre of 'idiotic art'. It is not the merely 'disruptive' elements of Calle's work that appeal to me. It is her audacity in making the kind of work she wants to make and not being bothered about how anyone chooses to label it. Calle herself was invited to contribute to this Forum, but she had other priorities; the rest of us can debate and define her all we like.

In my text, I do not claim to be stealing from Calle in my own practices as an anthropologist. But with her clear disavowal of any desire to contribute to the field of anthropology, I wind up stealing Calle herself, situating her in a context she never intended to inhabit, doing to her what she so often does to others. I am also suggesting that we consider-seriously-what anthropologists might gain by employing something of Calle's gall, her wit, her way of peering critically and reflexively at a social situation through disquieting lenses, and her inventive treatments of images, objects, and words to convey what she sees and feels. Of course, Calle is not the only artist out there for the taking, confirmed by the growing constellations of projects that experiment with what the spaces between contemporary art and anthropology might look like and mean. And what is particularly exciting is that much of that work still remains to be made and seen. 